\title{
The Food and Drug Administration Office of Women's Health: Impact of Science on Regulatory Policy: An Update
}

\author{
Merina Elahi, BS, Noha Eshera, BS, ${ }^{1}$ Nkosazana Bambata, BS, Helen Barr, MD, \\ Beverly Lyn-Cook, $\mathrm{PhD}^{3}$, Julie Beitz, MD, Maria Rios, $\mathrm{PhD}$, Deborah R. Taylor, $\mathrm{PhD}$, \\ Marilyn Lightfoote, MD, PhD, ${ }^{2}$ Nada Hanafi, MS,2, Lowri DeJager, PhD, Paddy Wiesenfeld, PhD, \\ Pamela E. Scott, PhD, Emmanuel O. Fadiran, PhD, and Marsha B. Henderson, MCRP ${ }^{1}$
}

\begin{abstract}
The U.S. Food and Drug Administration Office of Women's Health (FDA OWH) has supported women's health research for $\sim 20$ years, funding more than 300 studies on women's health issues, including research on diseases/conditions that disproportionately affect women in addition to the evaluation of sex differences in the performance of and response to medical products. These important women's health issues are studied from a regulatory perspective, with a focus on improving and optimizing medical product development and the evaluation of product safety and efficacy in women. These findings have influenced industry direction, labeling, product discontinuation, safety notices, and clinical practice. In addition, OWH-funded research has addressed gaps in the knowledge about diseases and medical conditions that impact women across the life span such as cardiovascular disease, pregnancy, menopause, osteoporosis, and the safe use of numerous medical products.
\end{abstract}

\section{Introduction}

S NCE ITS INCEPTION in 1906, Food and Drug Administration (FDA) has been committed to addressing women's health, as illustrated by key events in its history, such as FDA's reversal of guidance that effectively excluded women of childbearing potential (WOCBP) from clinical studies. $^{1-3}$ In the past 20 years alone, the FDA fulfilled a congressional mandate by establishing the Office of Women's Health (FDA OWH) in $1994^{4}$ and published guidance on the inclusion of women in clinical trials and evaluation for sex differences in response to medical products. ${ }^{3,5}$ More directly related to clinical care, thousands of mammography facilities were inspected and certified and vaccines approved to prevent cervical cancer and much more. Most recently, in August 2014, the FDA released an action plan ${ }^{6}$ to improve the collection and availability of subgroup data and analyses in clinical trials used to support marketing applications submitted to FDA. This not only provides the opportunity for a significant public health impact for women but for other demographic groups as well.

Throughout its history, the FDA OWH has protected and advanced the health of women through policy, science, and outreach and advocated for the inclusion of women in clinical trials and for the appropriate analyses of trial data for sex effects. ${ }^{7}$ One way in which OWH fulfills this mission is by funding research relevant to women's health, with an emphasis on funding studies that have the potential to provide scientific foundation for regulatory decision-making about FDA-regulated medical products, enable innovation in medical product development, and address emerging women's health issues. The most cutting-edge scientific understanding available informs FDA's regulatory decisions and public health actions. ${ }^{8}$ In addition, the ongoing influence of factors such as sex, age, and race/ethnicity on the safety and efficacy of medical products is evaluated throughout the

\footnotetext{
${ }^{1}$ Office of Women's Health (OWH), Food and Drug Administration, Silver Spring, Maryland.

${ }^{2}$ Center for Devices and Radiological Health (CDRH), Food and Drug Administration, Silver Spring, Maryland.

${ }^{3}$ National Center for Toxicological Research (NCTR), Food and Drug Administration, Jefferson, Arkansas.

${ }^{4}$ Center for Drug Evaluation and Research (CDER), Food and Drug Administration, Silver Spring, Maryland.

${ }^{5}$ Center for Biologics Evaluation and Research (CBER), Food and Drug Administration, Silver Spring, Maryland.

${ }^{6}$ Center for Food Safety and Applied Nutrition (CFSAN), Food and Drug Administration, Silver Spring, Maryland.
}

(c) Merina Elahi, et al. 2016; Published by Mary Ann Liebert, Inc. This Open Access article is distributed under the terms of the Creative Commons Attribution Noncommercial License (http://creativecommons.org/licenses/by-nc/4.0/) which permits any noncommercial use, distribution, and reproduction in any medium, provided the original author(s) and the source are credited. 
product life cycle. ${ }^{3,5}$ This scientific foundation used for evaluation and decision-making is built, in part, by research that is conducted in-house and through collaboration with other agencies and academia. ${ }^{8}$

OWH has funded more than 300 research projects to support women's health since the Office was created in 1994. The scientific findings have been disseminated by more than 250 peer-reviewed journal publications ${ }^{9}$ and hundreds of scientific presentations at national and international conferences. Previously, Obias-Manno et al. ${ }^{10}$ provided a description of regulatory impacts from projects funded by the FDA OWH during its first decade. Using a few examples, this report focuses on contributions that the FDA OWH-funded research has made during its second decade and also discusses some older contributions not previously discussed by Obias-Manno et al. ${ }^{10}$ (Table 1). ${ }^{11-29}$ The research has elucidated women's health issues throughout the life cycle of several medical products, from premarket to postmarket.

\section{Preclinical Research}

Many medical products fail during advanced stages of development because of toxicities that could potentially be identified before human exposure, but which remain elusive because of the unavailability of predictive preclinical models. ${ }^{30}$ Importantly, some studies have suggested that women are more susceptible to drug-induced liver injury, ${ }^{31}$ which is a leading cause of drug nonapprovals. Better preclinical models using cell culture, male and female animals, and computational methods could improve the selection of successful product candidates and thereby reduce development costs and avoid exposing clinical trial participants to unnecessary harm. In the OWH research portfolio, nonclinical models are an important adjunct in gathering information about pregnant women for countermeasure efforts, assessing organ-specific toxicities from drugs and providing evaluation methods for device manufacturers to use for new technologies. For example, these evaluation methods for devices may include tools to measure excess radiation to organs such as the breast during imaging procedures and the testing of device performance under variable conditions. The latter is important since it has been reported that sex differences in anatomy and physiology can contribute to an increased risk for distortion or breakdown of certain devices in the body. ${ }^{32}$

\section{Examining drug toxicity: tamoxifen, toremifene}

OWH funded research on preclinical models to investigate toxicity in tamoxifen users. ${ }^{33,34}$ This research was preceded by reports of endometrial malignancies in women undergoing breast cancer treatment with tamoxifen ${ }^{35}$ when the mechanism of action was unknown. It was estimated that up to $20 \%$ of women taking tamoxifen developed endometrial polyps, glandular hyperplasia, adenomyosis, or leiomyomata ${ }^{36}$ One project identified DNA adduct standards for tamoxifen, ${ }^{34}$ and led to further study of DNA adducts found in rat livers, contributing to a better understanding of tamoxifen's effect on the liver and uterus. Publications of these findings and other published findings contributed to a labeling warning for tamoxifen about the potential for development of uterine cancer and liver toxicity. ${ }^{37}$

Toremifene was synthesized to develop a less harmful drug for breast cancer. ${ }^{11}$ However, an animal study funded by
OWH found the effects of toremifene on the developing uterus to be similar to those of tamoxifen at similar exposures and concluded that toremifene may be a human developmental toxicant. These findings contributed to the labeling of toremifene, which states under the "Use in Specific Populations, Pregnancy Section" that, "In rodent models of fetal reproductive tract development, toremifene produced inhibition of uterine development in female pups similar to effects seen with diethylstilbestrol (DES) and tamoxifen". ${ }^{38}$

\section{Research to Improve Clinical Trials}

Research funded by FDA OWH to improve the design of clinical trials has focused on the development of tools to better predict safety during clinical trials before medical products reach the market. Some of these tools include novel methodologies to improve subpopulation analysis by sex and to improve drug dosing in special populations for which clinical study is difficult, such as in pregnant women. Research in this area has included the use of pharmacogenomics, pharmacogenetics, the identification of biomarkers, and the development of predictive quantitative models. Other research projects that the FDA OWH has supported include investigations on the recruitment, retention, and participation of diverse women in clinical trials. Enhancing the availability of clinical trial data on women will help FDA identify sex differences in the safety or efficacy of medical products.

\section{Improving clinical trial design: lung cancer, HIV-1}

Oncology drugs have a low rate of successful drug development compared to other therapeutic areas ${ }^{39}$ and there is a need for novel treatments for neoplasms such as lung cancer. Lung cancer is the leading cause of cancer-related death in American women. ${ }^{40}$ An FDA OWH-funded project created a quantitative survival model to aid in the development of potential drugs for non-small cell lung cancer (NSCLC) by linking early tumor size to patient survival. ${ }^{12}$ The model is used to screen drug candidates early in development and can optimize phase III clinical trials by improving the trial design and dose selection. ${ }^{12,41}$ The model incorporated significant risk factors of mortality from the results of four NSCLC clinical trials submitted to the FDA. Baseline tumor size, the change in tumor size at week 8, and the baseline Eastern Cooperative Oncology Group (ECOG) performance status score were used in the model. In early 2010, the model was used to predict the results of an ongoing phase III trial (Amgen MONET1) of motesanib plus chemotherapy in NSLC, finding that the treatment being tested may have similar survival benefits as the standard treatment. ${ }^{42}$ Accordingly, in March 2011, Amgen announced that the study had failed. This model, although specific to lung cancer, has also led to the initiation of a similar ongoing project for breast cancer (Y. Wang, personal communication) and similar models can help support decisions in future early drug development.

FDA OWH funding will also facilitate future clinical trials for HIV-1 vaccine candidates. These candidates contain viral components, which cause responses in trial participants that elicit positive results from HIV serodetection tests. An inexpensive and high-throughput assay, HIV-Selectest, has been developed to differentiate between native HIV infections and responses triggered by the vaccine candidate. ${ }^{43}$ This 


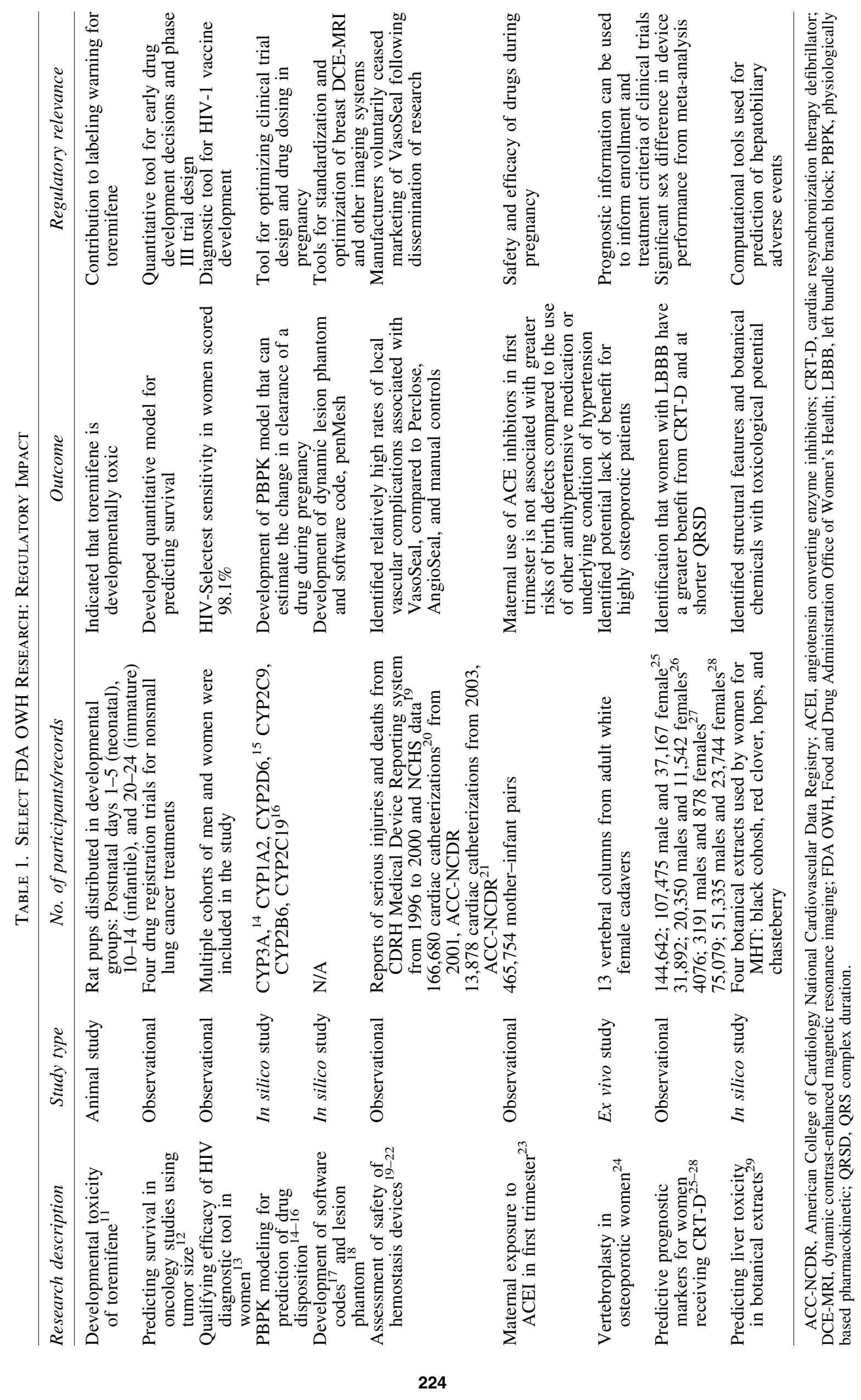


powerful tool can be used for population screening by blood banks and can protect participants of HIV clinical trials from the physical, emotional, and economic or social harms of being falsely diagnosed with an HIV infection. ${ }^{13,43} \mathrm{OWH}$ funded a portion of the tool's development to guarantee that it would have high sensitivity in both women and men. The tool is undergoing redevelopment to improve its function across multiple clades of HIV-1 virus, so that it can be used to help manage global aspects of the HIV epidemic. ${ }^{44}$ Although still under development, it is expected to be used in upcoming large HIV vaccine clinical trials.

\section{Modeling and simulation, early detection: breast cancer}

Women exposed to X-ray radiation from computed tomography $(\mathrm{CT})$ scanners have a higher lifetime attributable risk of cancer incidence than men of the same age. ${ }^{45}$ In addition, the US Preventative Services Task Force recommends that women aged 50 through 74 years undergo routine screening mammography every 2 years, ${ }^{46}$ thereby exposing women to potentially more lifetime radiation exposure than men. Modeling and simulation of radiological devices can help develop novel methodologies to limit radiation doses to women during imaging procedures such as breast cancer screening. These methodologies can serve as evaluation tools for new imaging systems.

Mammography, well established as the gold standard of breast cancer screening, was the subject of many early OWHfunded projects. Over the past 20 years, the Mammography Quality Standards Act (MQSA) program at the FDA has ensured that mammography facilities across the country meet baseline quality standards. ${ }^{47}$ MQSA is an example where regulations helped drive technology. By setting baseline standards for mammography equipment, older equipment was phased out and companies ensured that new equipment would exceed the standards.

FDA OWH has also funded projects looking into the optimization of other breast cancer imaging systems, such as dedicated breast tomographic X-ray breast imaging systems. $^{48,49}$ These new tomographic technologies are already improving the detection of breast cancer in women for whom mammography is not as sensitive, such as women with dense breasts. $^{50}$

Studies funded by FDA OWH supported the development of computer codes to simulate the performance of clinical Xray imaging systems. This technology allows developers and academia to more accurately predict radiation doses in patients with the use of detailed anatomical phantoms. These simulations enable the study of emerging breast imaging modalities as well as the improvements of current ones to minimize radiation dose received by the patient. The investigators, using this simulation technology, created a database of radiation doses that an organ is predicted to receive during CT scans. ${ }^{51}$

Another FDA OWH-supported project produced breast phantoms for dynamic contrast-enhanced magnetic resonance imaging (DCE-MRI) that mimic benign and malignant lesions in an image background that has the same texture properties as those found in patient breast images. ${ }^{18}$ DCEMRI is used to detect breast cancer and to screen high-risk patients. The methodology described in this research for characterizing phantoms has allowed researchers to improve the standardization of DCE-MRI protocols and evaluate image quality at different magnetic field strength and contrast agent doses to optimize the detection of breast lesions.

\section{Improving drug dosing: use of prescription medications by pregnant women}

Pregnant women are often excluded from clinical trials for various ethical reasons and complications of taking medications during pregnancy that may not be known at the time of drug approval. ${ }^{52}$ This may introduce uncertainty and anxiety for pregnant women. In addition, although little information may be available from clinical trials about the safety and efficacy of medication for both mother and fetus, pregnant women are often exposed to prescription medications. One study found that women in up to $64 \%$ of deliveries were exposed to prescription medication during pregnancy. ${ }^{53}$ In $2006,49 \%$ of pregnancies were unintended ${ }^{54}$ and medical problems may occur or persist throughout any pregnancy. As a result, it is essential to overcome the knowledge gaps with regard to medication use in pregnancy; one strategy is to use predictive modeling.

Modeling using in silico or in vitro methods can provide predictions on how pregnant women might respond to certain drugs without having to expose them to the drug in clinical trials. FDA OWH funded the development of physiologically based pharmacokinetic (PBPK) models to predict the effect of pregnancy on drug disposition. This modeling approach incorporates both drug-specific parameters and physiological parameters. The application of PBPK models is prevalent in drug development and can be applied to pregnant women to facilitate the design of dosing regimens ${ }^{55}$ as well as to study gender differences. ${ }^{56}$ These models can predict changes on the absorption, distribution, metabolism, and excretion of drugs during stages of pregnancy. FDA scientists constructed PBPK models and simulated drugs undergoing different metabolic pathways while incorporating the changes that occur in hepatic cytochrome P-450 (CYP-450) enzymes during pregnancy. ${ }^{14-16}$ Other valuable data on pregnant women, such as real-world data, can be gathered from postmarket data sources and will be discussed in the next section. Many of the FDA-OWH-funded studies about drug exposure during pregnancy have analyzed mother-fetus outcomes using postmarket data. ${ }^{23,57-59}$

\section{Postmarketing Studies for Medical Products}

Some adverse events are not identified until products are marketed and used in real-world populations. Clinical trials cannot fully address long-term safety concerns and often enroll patients with more homogenous demographics and disease status than are found in real-world patients. These concerns can be addressed by the robust postmarket research efforts at the FDA. Postmarket research uses multiple data sources, including FDA Adverse Event Reporting System (FAERS) electronic health records, the Medical Device Reporting (MDR) system, and the Manufacturer and User Facility Device Experience (MAUDE) database and registries. In addition to surveillance using bioinformatics, FDA OWHfunded research has used empirical approaches to answer concerns about safety or efficacy such as those relating to offlabel use. Importantly, women have received more off-label 
prescriptions than men as they are more likely to be treated for or are disproportionately affected by disorders that are associated with high rates of off-label prescribing, such as fibromyalgia. ${ }^{60}$ FDA uses results of postmarket research to make regulatory decisions leading to safety communications to physicians and patients, warnings to medical product manufacturers, labeling changes and recalls of medical products from the market. Postmarket research may also encourage future approvals for new medical products and support modifications of existing device technology. ${ }^{61}$

\section{Identifying safety concerns using electronic health records: antihypertensives in pregnancy and hemostasis devices}

Postmarket data collection is an important source for gathering evidence to support decision-making regarding the safe use of medications during pregnancy, some of which is collected through registries. In addition to maintaining a registry webpage, as discussed in Obias-Manno et al., ${ }^{10}$ in May 2014, FDA OWH cofunded, along with the FDA Center for Biologics Evaluation and Research (CBER) and the FDA Center for Drug Evaluation and Research (CDER), a public meeting where the challenges of increasing the availability of human pregnancy data were examined. Methods for improving enrollment and retention of pregnant women in registries as well as other methods for evaluating the postapproval safety of medical products in pregnant women were considered at the public meeting. ${ }^{62}$

FDA OWH contributed funds to a project investigating risks of maternal use of angiotensin converting enzyme (ACE) inhibitors during the first trimester ${ }^{23}$ through profiles of maternal-infant pairs. The study by $\mathrm{Li}$ et al. ${ }^{23}$ was conducted in collaboration with the Agency for Healthcare Research and Quality (AHRQ) Effective Healthcare Program, ${ }^{63}$ which helps healthcare professionals make evidence-based treatment decisions for their patients. The study was performed to verify findings from a previous OWH-funded study conducted by Cooper et al. ${ }^{64}$ which observed an increased risk of major congenital malformations associated with maternal use of ACE inhibitors during the first trimester. ${ }^{64}$ This previous finding was not confirmed by $\mathrm{Li}$ et al. ${ }^{23}$ who found that ACE inhibitors, other antihypertensive medications, and the underlying hypertension itself were all associated with a similar increased risk of major congenital malformations. ${ }^{23}$ The findings suggested that hypertension itself is likely what increased the risk of malformations rather than the drugs used to treat it. This study, along with other evidence, allowed FDA to conclude that maternal use of ACE inhibitors during the first trimester is not associated with greater risks of birth defects compared to the use of other antihypertensive medication. ${ }^{65,66}$ This evidence-based information is useful for clinicians prescribing medication for hypertension in pregnant women, a very common disease associated with pregnancy. $^{67}$

Between 1996 and 2000, the FDA Center for Devices and Radiological Health (CDRH) received 1880 reports of serious injuries or deaths associated with the use of certain hemostasis devices used to prevent bleeding from the femoral artery following cardiac catheterization for diagnostic or therapeutic purposes. ${ }^{19}$ The estimated risk of reported serious injuries and deaths were two to three times greater in women for hemorrhage and hematoma. ${ }^{19}$ FDA OWH supported further investigation of the relative risks of reported serious injury and death following the use of two main types of hemostasis devices, collagen plug devices and suture devices, using 2001 catheterization laboratory discharge data collected from the American College of Cardiology National Cardiovascular Data Registry (ACC-NCDR). This larger study also demonstrated a higher relative risk of complications in women. ${ }^{20}$ A second phase of the study expanded on the findings and involved the investigation of specific collagen plug devices. Importantly, the study revealed relatively high rates of local vascular complications associated with VasoSeal, compared to Perclose, AngioSeal, and manual controls. ${ }^{21}$ It is important to note that the manufacturer voluntarily ceased marketing VasoSeal for all users. ${ }^{68}$

\section{Developing better patient selection criteria: vertebroplasty, cardiac resynchronization therapy}

Some FDA OWH-funded research projects looked at developing better patient selection criteria for medical device use in women, supporting FDAs initiatives to promote personalized or precision medicine. Individualized treatment may allow patients to receive more therapeutic benefit from medical products with less side effects or associated adverse events.

Vertebral fracture is a significant women's health issue because it is the most common injury resulting from osteoporosis, which occurs three times higher in women. ${ }^{69}$ Vertebroplasty is one treatment for these fractures, which involves injections of acrylic bone cement into the vertebral body. The procedure can be associated with serious complications resulting from cement leakage, leading to concerns about safety and efficacy. In addition, some of these concerns arose from acrylic bone cement being routinely used off-label for the procedure. One FDA OWH-funded project performed an ex vivo biomechanical study to examine the mechanical benefit of vertebroplasty in vertebral bodies of varying bone mineral densities. ${ }^{24}$ The study demonstrated that improvements in vertebral body stiffness and strength were significantly dependent on bone density. This was one of the first studies to show that for severely osteoporotic patients, there may be limited benefit to adding additional cement beyond that needed for fracture reduction to increase the strength of a vertebral body. Understanding this relationship between restorative benefit and osteoporotic status can assist in decision-making regarding patient selection, potentially minimizing risks of adverse events and maximizing treatment benefits in osteoporotic women. ${ }^{24}$

A key demonstration in the importance of improving patient selection criteria arose while investigating sex-specific criteria in a study examining cardiac resynchronization therapy defibrillators (CRT-Ds), a treatment for patients with heart failure. Previous clinical studies demonstrating longterm survival after CRT-D had limited subgroup analysis since women were underrepresented. To investigate if women showed similar or better long-term survival following CRT-D compared to men, FDA scientists completed a study on 144,642 Medicare patients receiving CRT-D. ${ }^{25}$ This study, to the investigators' knowledge, was the first time that the presence of left bundle branch block (LBBB) was shown to predict better long-term survival benefit in women than 
men receiving CRT-D. This survival benefit for women was also observed in other studies that the group conducted using more diverse, real-world CRT-D populations with larger proportions or populations of women, ${ }^{26,28,70}$ also finding that CRT-D was associated with lower mortality in both men and women with LBBB. ${ }^{28}$ This example is significant because FDA OWH's interest in sex differences is not limited to identifying areas where women have poorer outcomes than men but also to identify where treatments are potentially more beneficial for women and are perhaps underutilized because of concerns about insufficient safety and efficacy.

Also, these FDA investigators conducted a meta-analysis of three CRT-D trials that were submitted to the FDA in premarket applications (PMAs) review, demonstrating that pooling individual patient data from multiple clinical trials can provide significant sex difference information, which may be masked by an underrepresentation of women in individual clinical trials. ${ }^{27,71}$ Recent professional guidelines for CRT-D based on a meta-analysis that included $80 \%$ men, recommended CRT-D for use in patients with $\mathrm{LBBB}$ and a QRS complex duration (QRSD) of 150 mseconds or longer. ${ }^{27,72}$ The QRS complex depicts ventricular depolarization on an electrocardiogram (ECG). The study, however, revealed that women with LBBB at a QSRD of 130-149 mseconds significantly benefited from CRT-D. This is especially important as women currently receive CRT-D less often than men, and a change in practice guidelines could increase CRT-D use and benefits in women. The availability of sex-specific safety and efficacy data is critical to inform patient diagnostic and therapeutic decision-making.

\section{Predictive methodology development: dietary supplements}

Dietary supplements are not subject to FDA approval before being marketed but the FDA may proceed with regulatory action if it can be shown that the supplement is unsafe. ${ }^{73}$ Past FDA actions include the banning of supplements containing ephedra in $2004^{74}$ and the issuance of warning letters to manufacturers of supplements containing methylhexanamine (also known as dimethylamyline or DMAA) in $2012 .^{75} \mathrm{Be}-$ cause of the prevalence of use by women and because there is limited efficacy and safety information on supplements in comparison to drugs, FDA OWH has funded research on dietary supplements over the years, including past research on ephedra containing weight loss supplements. ${ }^{76}$

One reason that women take supplements is to relieve menopausal symptoms. It is estimated that up to $79 \%$ of women ages 40-60 use botanical dietary supplements. ${ }^{77}$ Widespread use enhances concerns about the safety of these supplements. For example, one of the supplements investigated by an FDA OWH-funded study, black cohosh, had been reviewed by the United States Pharmacopeia (USP) ${ }^{78}$ and National Institutes of Health (NIH) Office of Dietary Supplements ${ }^{79}$ due to several reports of hepatotoxicity. Black cohosh, as well as other botanicals used most often for menopause (chasteberry, hops and red clover), were studied in the FDA OWH-funded project that used computational modeling to investigate hepatotoxicity. ${ }^{29}$ Chemical constituents of these four botanicals were screened in silico by software programs using Quantitative Structure-Activity Relationship (QSAR) models and cheminformatics to pre- dict hepatobiliary adverse events. The FDA investigator compiled a list of lead chemicals and structural motifs that commonly contributed to predictions of adverse events, which may be of use for future experimental designs. Predictive methodology developed in this research was used by the USP, an international organization that creates official standards for dietary supplements to support its safety assessment work.

\section{Ongoing Research}

FDA OWH is also funding projects that address emerging women's health issues. In 2013, FDA issued a gluten-free rule and set a threshold of $<20$ ppm gluten in foods labeled "gluten-free" ${ }^{80}$ One project that is currently being funded by FDA OWH is the development of an in vitro bioassay using human intestinal epithelial cell lines, ${ }^{81-84}$ thus providing a method to assess both intact and hydrolyzed (e.g., beer) gluten to better evaluate the presence of gluten in foods so that they do not cause harmful immunologic responses in people who have gluten sensitivity or those with Celiac disease. Celiac disease is diagnosed two-to-three times more frequently in women. ${ }^{85}$

Additional ongoing projects include investigations on biomarkers for drug-induced cardiotoxicity. After two decades of FDA OWH-funding research, heart disease in women still remains a main focus of research. Cardiac QT interval prolongation and its association with Torsade de Pointes (TdP), a ventricular tachycardia, was the subject of many early FDA OWH-funded projects. ${ }^{86-89}$

Earlier research funded by FDA OWH found that certain drugs caused QT interval prolongation and TdP more often in women than men. ${ }^{86}$ Eight of the ten drug withdrawals between 1997 and 2001 posed higher risks for women and 4 of those 10 were associated with the development of $\mathrm{TdP} .^{90}$ Recent FDA research is investigating novel ECG markers to predict benign versus malignant QT interval prolongation, studying differences in mechanisms of QT interval prolongation between women and men and finding ways to mitigate a drug's potential to cause such prolongation. ${ }^{91-94}$ This research not only has the potential to protect women from TdP but also has the potential to optimize drug development. FDA OWH is partnering with other researchers both internal and external to FDA to not only understand the sex differences but also to identify drugs that will promote TdP as well as develop drugs to prevent the TdP.

Cardiotoxicity associated with noncardiovascular drugs is another area of FDA OWH-supported research. Following clinical reports of cardiac dysfunction in breast cancer patients treated with trastuzumab, ${ }^{95}$ a humanized monoclonal antibody approved for the treatment of HER2-positive breast cancer, an ongoing project is investigating the mechanism of trastuzumab-induced cardiotoxicity through the development of animal models and cell culture models. ${ }^{96}$ This research revealed that trastuzumab significantly alters the expression of myocardial genes essential for DNA repair and cardiac and mitochondrial functions, which is associated with impaired left ventricular performance in mice coupled with significant ultrastructural alterations in cardiomyocytes detected by electron microscopy. Potential biomarkers for trastuzumabinduced cardiotoxicity have been identified in a mouse model. ${ }^{96}$ 


\section{Inclusion of Women in Clinical Trials and Sex Analyses}

Funding scientific research to protect and advance the health of women is only part of FDA OWHs mission. The Office is also tasked with advocating for the participation of women in clinical trials and for sex, gender, and subpopulation analysis. Adequate representation of demographic groups by sex, age, and race/ethnicity in clinical trials is necessary to make comprehensive safety and efficacy assessments of medical products so that evidence-based clinical decisions can be made that are applicable to all patients who will use the medical product following approval. Great strides have been made in the inclusion of women in clinical trials submitted to FDA as noted by the U.S. Government Accountability Office (GAO) in 2001. ${ }^{97}$ This improvement has also been observed by FDA OWH, which has, since its inception, been looking at the participation of women in select early- and late-phase clinical trials.

A 2001 GAO report on new drug applications (NDAs) approved between 1998 and 2001 found that women comprised $22 \%$ of clinical trial participants in early-phase trials. ${ }^{97}$ FDA studies showed that the inclusion of women in earlyphase trials was $24 \%$ in NDAs approved between 2000 and $2002^{98}$ and $30.6 \%$ in new molecular entities approved from 2006 to 2007 . $^{99}$

The 2001 GAO report also found that women comprised $56 \%$ of participants in late-phase clinical trials. ${ }^{97}$ The participation of women in late-phase trials was $51 \%$ in NDAs approved by FDA between 2000 and 2002, ${ }^{98} 43 \%$ in NDAs approved between 2007 and 2009, ${ }^{100}$ and $45 \%$ for NDAs approved between 2010 and 2012, ${ }^{101}$ and therefore, Eshera et al. ${ }^{101}$ concluded that women's participation has remained steady overall and can vary because products with different indications are submitted to the FDA for approval every year. In addition to surveying NDAs, funded projects have also surveyed biologics license applications and PMAs. ${ }^{5,102,103} \mathrm{It}$ should be noted that while the inclusion of women varies by product, the conduct of sex analyses is addressed in some way in the vast majority of FDA-approved medical products as indicated by FDA in a congressionally mandated report. ${ }^{104}$ The FDA report looked at the extent to which demographic subgroups participated in clinical trials and of subgroup analyses for safety and effectiveness. ${ }^{104}$ The development of this report was led by FDA OWH and involved participation by all medical product centers and led to an Action Plan to encourage the inclusion of subgroup populations in clinical trials. ${ }^{6}$ FDA OWH provided support for a key item of the Action Plan, an FDA website providing snapshot information on the demographic make-up of certain clinical trials for approved drugs. 105

As it is a fundamental part of FDA OWHs mission, significant efforts have been made to improve the rates of participation of women in clinical trials. These efforts include supporting conferences and workshops with other government agencies, academia, professional societies, and industry. Two FDA workshops ${ }^{106,107}$ that were supported by FDA OWH concerning women in cardiovascular medical product trials ultimately informed the preparation of the FDA guidance document entitled "Evaluation of Sex-Specific Data in Medical Device Clinical Studies," 5 which was issued in August 2014. This guidance includes recommendations for enrolling women in device clinical studies, for reporting sex- specific data, and for conducting sex analyses. FDA OWH also held a conference with the Society for Women's Health Research to discuss best practices for the recruitment and retention of women and minorities in clinical research ${ }^{108}$ and the conference produced a white paper. ${ }^{109}$ Recommendations from the white paper include raising awareness about clinical trial participation through community-based participatory research.

\section{Discussion}

The FDA is tasked with the evaluation of medical product safety and efficacy throughout the product's life cycle. As the examples reported earlier demonstrate, additional scientific research can provide data on women or on sex differences especially where data are lacking to improve FDAs evaluation of medical products. Since its inception in 1994, FDA OWH has become an important and crucial resource within FDA to help answer regulatory questions. In addition, research funded by the FDA OWH is aligned with the FDA strategic plan for advancing regulatory science ${ }^{8}$ to enhance the availability of safe and effective medical products for women and men (Table 2). ${ }^{27,30,79,97,110-124}$ The FDA OWH has fostered innovation in the development of new tools to obtain data on women and to investigate potential sex differences in outcomes during medical product testing and development. Pooling together individual clinical trial data submitted to the FDA allowed investigators to unmask sex differences in CRT-D outcome that were not apparent from the individual analysis of each study. PBPK modeling allowed investigators to gather important parameters on medications used by pregnant women. These are key examples of how developing novel methodologies allows FDA to obtain data on women. Research funded by FDA OWH has been incorporated into regulatory documents such as guidance for industry and FDA staff (Table 3).

Collaborations with FDA centers and other groups outside of the Agency have been leveraged to address unmet needs in regulatory science regarding women's health. In addition, the outreach activities of the office, although not the subject of this report, provide a substantive and far-reaching line of bidirectional communication between the FDA, women, and other key constituents. Examples of outreach initiatives include "My Medicines" with a network of national organizations and chain drug stores to help women keep record of their medications, as well as video novellas called "Nunca Más," ${ }^{125}$ developed to educate Hispanic women and their families on medication safety. The College Women's Campaign, a national initiative, ${ }^{126}$ aims to increase young women's access to FDA health information. Furthermore, a number of health literacy publications ${ }^{127}$ in several languages have been distributed to millions of women.

Although the 20-year bench mark of FDA OWHs founding has allowed the Office to look back at past activities, the pressing need from current health crises for women provides the impetus for the Office to look forward with new directions. Twenty years ago, there was limited knowledge about women's health and sex discrepancies in the safety and efficacy of medical products. The progress in women's health research in the past two decades has identified particularly critical areas of women's health research that need to be investigated, enabling the FDA OWH to fund research in a 
FDA science priority areas of regulatory science

1. Modernize toxicology to enhance product safety

2. Stimulate innovation in clinical evaluations and personalized medicine to improve product development and patient outcomes

3. Support new approaches to improve product manufacturing and quality

4. Ensure FDA readiness to evaluate innovative emerging technologies

5. Harness diverse data through information sciences to improve health outcomes

6. Implement a new prevention-focused food safety system to protect public health

7. Facilitate development of medical countermeasures to protect against threats to U.S. and Global Health and Security

8. Strengthen social and behavioral science to help consumers and professionals make informed decisions about regulated products
Science funded by the $\mathrm{OWH}$

Developing a knowledge base for better understanding of sex biased drug-induced liver injury $^{31}$

Identifying a biomarker for trastuzumab-induced cardiotoxicity ${ }^{96}$

Increasing the understanding of sex differences in drug toxicity mechanisms at the level of gene expression of drug-metabolizing and transporting enzymes ${ }^{110}$

Improving the use of biomarkers with comprehensive study of sex differences in F344 rat kidney gene expression ${ }^{111-115}$

Identifying a gene expression signature for systemic lupus erythematosus ${ }^{116}$

Quantifying the variability in interpretation of computer-aided digital microscopy for $H E R 2 / n e u$ expression in breast tissue ${ }^{117}$

Using liquid chromatography for simultaneous determination of estradiol, estriol, estrone, and progesterone ${ }^{18}$

Identifying an approach to improve condom water leak testing ${ }^{119}$

Development of artificial plaques to investigate relationships between composition of plaque and drug transport ${ }^{120}$

Nanoparticle effects on induction of proinflammatory responses to Candida albicans by cultured vaginal epithelial cells ${ }^{119}$

Safety and efficacy of iron oxide nanoparticles used as MRI contrast agents for breast cancer imaging ${ }^{121}$

Pilot study testing of a CDISC standard format in vaccine products ${ }^{119}$

Developing methodology to improve signaling for data mining FDAs Spontaneous

Reports database ${ }^{122}$

Combining data from multiple trials submitted to the FDA to identify increased benefit for women using cardiac resynchronization therapy ${ }^{27}$

Determining strategies to improve listeriosis prevention messages for pregnant women ${ }^{123}$

Developing s bioassay to enhance surveillance of gluten-free status in foods ${ }^{81-84}$

Supporting the development of CFSAN Women's Health Internet Initiative (Phases I and II) 119

Investigation of hepatitis B immune globulin administration to pregnant women in animal mode for HBV prophylaxis ${ }^{124}$

Treatment of progressive vaccinia in a pregnant immunocompromised mouse model ${ }^{119}$

Development of a mouse model to mimic the response of female and pregnant human subjects to avian influenza infections and to evaluate the protective efficacy of pandemic $\mathrm{H} 5 \mathrm{~N} 1$ vaccines against highly pathogenic avian influenza ${ }^{119}$

Investigation of gender differences in the willingness to read and follow patient information ${ }^{119}$

Focus group testing to aid in the development of a uniform contraceptive efficacy table to aid in decision-making ${ }^{119}$

Focus group testing of labeling for tampons and barrier contraceptives ${ }^{119}$

Table 3. Regulatory Documents with Contributions from FDA OWH-Funded Research

\begin{tabular}{l}
\hline Guidance for industry: nonclinical evaluation of the potential for delayed ventricular \\
repolarization (QT interval prolongation) by human pharmaceuticals \\
Guidance for industry: E14 clinical evaluation of QT/QTc interval prolongation and \\
proarrhythmic potential for nonantiarrhythmic drugs \\
Guidance for industry and FDA staff: saline, silicone gel, and alternative breast implants \\
Draft guidance for industry: vaginal microbicides: development for the prevention of HIV \\
infection \\
Draft guidance for industry: drug interaction studies-study design, data analysis, \\
implications for dosing, and labeling recommendations \\
International Standard Safety Standard for CT: International Electrochemical Commission, \\
Medical electrical equipment: IEC 60601-2-44 \\
International Safety Standard for sunlamp products; International Electrochemical \\
Commission, Household and similar electrical appliances: IEC 60335-2-27 \\
Guidance for industry and FDA staff: evaluation of sex differences in medical device \\
clinical studies
\end{tabular}


more targeted way to support the most critically necessary research and to build upon preliminary research questions on which FDA scientists have already made headway. To accomplish these goals, a "Women's Health Research Roadmap" has recently been developed, which outlines FDA OWH research priorities and provides the foundation for funding future research. ${ }^{128}$ The Roadmap incorporates research priorities of FDA OWH stakeholders, and tackles questions the FDA product review Centers are facing, thereby optimizing FDA OWH research dollars and outcomes. ${ }^{128}$

It is sometimes necessary to collaborate with other agencies to solve regulatory questions, as the FDA is primarily a regulatory and not a research agency. FDA OWH continues to build collaborations with the National Institute of Health's Office of Research on Women's Health (ORWH) to engage in activities such as consortia and consensus development and education and research toward the shared interest in promoting awareness and understanding of the science behind sex-based differences. $^{129}$ FDA OWH is also embarking on collaboration on women's health initiatives at the international level with the Karolinska Institutet in Sweden, which is world-renowned for its sex and gender medicine research. ${ }^{130}$ The next era for the FDA OWH will show strengthened and broadened collaborations with other government agencies, academia, and the medical product industry to maximize the outcomes of women's health research, as it is essential to equip FDA with the cutting-edge scientific data, knowledge, and technology needed to address complex women's health issues, including those emerging and urgent, in its regulatory decision-making.

\section{Acknowledgments}

This project was supported, in part, by the appointments of Merina Elahi, Noha Eshera, and Nkosazana Bambata to the Research Participation Program at the Office of Women's Health, U.S. Food and Drug Administration, administered by the Oak Ridge Institute for Science and Education through an interagency agreement between the U.S. Department of Energy and FDA.

The authors thank the FDA scientists whose research works are discussed in this article for their comments and commitment to women's health research at FDA. They also thank Dr. Marietta Anthony and Dr. Marjorie Jenkins for their comments and insight and Tammie Brent-Howard and Leah Miller for their contributions to the summary of the projects.

\section{Author Disclosure Statement}

No competing financial interests exist.

\section{References}

1. Food and Drug Administration Office of Women's Health. 100 years of protecting and promoting women's health. Available at: www.fda.gov/forconsumers/byaudience/ forwomen/ucm118458.htm Accessed September 25, 2015.

2. U.S. Food and Drug Administration. Guidance for industry: General considerations for the clinical evaluation of drugs, 1977. Available at: www.fda.gov/downloads/ ScienceResearch/SpecialTopics/WomensHealthResearch/ UCM131196.pdf Accessed September 25, 2015.

3. Federal Register. Department of Health and Human Services. Guideline for the study and evaluation of gender differences in the clinical evaluation of drugs; Notice, July
1993, 58(139). Available at: www.fda.gov/downloads/ RegulatoryInformation/Guidances/UCM126835.pdf Accessed September 25, 2015.

4. Federal Register. Department of Health and Human Services Notice GN \#2260. Statement of organization, functions, and delegations of authority. Available at: www.gpo.gov/fdsys/ pkg/FR-1994-07-28/html/94-18389.htm Accessed September 25, 2015.

5. U.S. Food and Drug Administration. Guidance for industry and food and drug administration staff: Evaluation of sex-specific data in medical device clinical studies, 2014. Available at: www.fda.gov/downloads/Medical Devices/DeviceRegulationandGuidance/GuidanceDocu ments/UCM283707.pdf Accessed September 25, 2015.

6. U.S. Food and Drug Administration. FDA Report: Action plan to enhance the collection and availability of demographic subgroup data. Available at: www.fda.gov/downloads/Regu latoryInformation/Legislation/FederalFoodDrugandCosmetic ActFDCAct/SignificantAmendmentstotheFDCAct/FDASIA/ UCM410474.pdf Accessed September 25, 2015.

7. U.S. Food and Drug Administration. Office of Women's Health: Overview. Available at: www.fda.gov/AboutFDA/ CentersOffices/OC/OfficeofWomensHealth/default.htm Accessed September 25, 2015.

8. U.S. Food and Drug Administration. Strategic plan: Advancing regulatory science at FDA. Available at: www.fda .gov/downloads/scienceresearch/specialtopics/regulatory science/ucm268225.pdf Accessed September 25, 2015.

9. U.S. Food and Drug Administration. List of publications from OWH supported studies. Available at: www.fda.gov/ ScienceResearch/SpecialTopics/WomensHealthResearch/ ucm134681.htm Accessed September 25, 2015.

10. Obias-Manno D, Scott PE, Kaczmarczyk J, et al. The Food and Drug Administration Office of Women's Health: Impact of science on regulatory policy. J Womens Health (Larchmt) 2007;16:807-817.

11. Medlock KL, Branham WS, Sheehan DM. Effects of toremifene on neonatal rat uterine growth and differentiation. Biol Reprod 1997;56:1239-1244.

12. Wang Y, Sung C, Dartois C, et al. Elucidation of relationship between tumor size and survival in non-small-cell lung cancer patients can aid early decision making in clinical drug development. Clin Pharmacol Ther 2009;86:167-174.

13. Khurana S, Norris PJ, Busch MP, et al. HIV-Selectest enzyme immunoassay and rapid test: Ability to detect seroconversion following HIV-1 infection. J Clin Microbiol 2010;48:281-285.

14. Ke AB, Nallani SC, Zhao P, Rostami-Hodjegan A, Unadkat JD. A PBPK model to predict disposition of CYP3Ametabolized drugs in pregnant women: Verification and discerning the site of CYP3A induction. CPT Pharmacometrics Syst Pharmacol 2012;1:e3.

15. Ke AB, Nallani SC, Zhao P, Rostami-Hodjegan A, Isoherranen N, Unadkat JD. A physiologically based pharmacokinetic model to predict disposition of CYP2D6 and CYP1A2 metabolized drugs in pregnant women. Drug Metab Dispos 2013;41:801-813.

16. Ke AB, Nallani SC, Zhao P, Rostami-Hodjegan A, Unadkat JD. Expansion of a PBPK model to predict disposition in pregnant women of drugs cleared via multiple CYP enzymes, including CYP2B6, CYP2C9 and CYP2C19. Br J Clin Pharmacol 2014;77:554-570.

17. Badal A and Kyprianou I. PenMesh: Monte Carlo simulation of radiation transport in triangle meshes. Available 
at: http://code.google.com/p/penmesh/ Accessed September 25, 2015.

18. Freed M, de Zwart JA, Hariharan P, Myers MR, Badano A. Development and characterization of a dynamic lesion phantom for the quantitative evaluation of dynamic contrast-enhanced MRI. Med Phys 2011;38:5601-5611.

19. Tavris DR, Gallauresi B, Rich S, Bell C. Relative risks of reported serious injury and death associated with hemostasis devices by gender. Pharmacoepidemiol Drug Saf 2003;12:237-241.

20. Tavris DR, Gallauresi BA, Lin B, et al. Risk of local adverse events following cardiac catheterization by hemostasis device use and gender. J Invasive Cardiol 2004; 16:459-464.

21. Tavris DR, Dey S, Gallauresi BA, et al. Risk of local adverse events following cardiac catheterization by hemostasis device use-Phase II. J Invasive Cardiol 2005; 17:644-650.

22. Tavris DR, Gallauresi BA, Dey S, Brindis R, Mitchel K. Risk of local adverse events by gender following cardiac catheterization. Pharmacoepidemiol Drug Saf 2007;16: 125-131.

23. Li DK, Yang C, Andrade S, Tavares V, Ferber JR. Maternal exposure to angiotensin converting enzyme inhibitors in the first trimester and risk of malformations in offspring: A retrospective cohort study. BMJ 2011;343:d5931.

24. Graham J, Ahn C, Hai N, Buch BD. Effect of bone density on vertebral strength and stiffness after percutaneous vertebroplasty. Spine (Phila Pa 1976) 2007;32:E505-E511.

25. Loring Z, Canos DA, Selzman K, et al. Left bundle branch block predicts better survival in women than men receiving cardiac resynchronization therapy: Long-term followup of approximately 145,000 patients. JACC Heart Fail 2013;1:237-244.

26. Zusterzeel R, Curtis J, Canos D, et al. Sex-specific mortality risk by QRS morphology and duration in patients recieving CRT: Results from the NCDR. J Am Coll Cardiol 2014;64:887-894.

27. Zusterzeel R, Selzman KA, Sanders WE, et al. Cardiac resynchronization therapy in women: US Food and Drug Administration meta-analysis of patient-level data. JAMA Intern Med 2014;174:1340-1348.

28. Zusterzeel R, Spatz ES, Curtis JP, et al. Cardiac resynchronization therapy in women versus men: Observational comparative effectiveness study from the National Cardiovascular Data Registry. Circ Cardiovasc Qual Outcomes 2015;8(2 Suppl 1):S4-S11.

29. Wang YJ, Dou J, Cross KP, Valerio J. Computational analysis for hepatic safety signals of constituents present in botanical extracts widely used by women in the United States for treatment of menopausal symptoms. Regul Toxicol Pharmacol 2011;59:111-124.

30. U.S. Food and Drug Administration. Innovation or stagnation: Challenge and opportunity on the critical path to new products. Available at: www.fda.gov/ScienceResearch/ SpecialTopics/CriticalPathInitiative/CriticalPathOpportunities Reports/ucm077262.htm Accessed September 25, 2015.

31. Tong W, Shi Q, Salminen W, et al. Unraveling sex differences in drug-induced liver injury. Systems Toxicology, Systems. (Section editors: Casciano DA, Sahu SC) General, applied and systems toxicology 2011. Published online. Available at: http://onlinelibrary.wiley.com/doi/ 10.1002/9780470744307.gat226/abstract Accessed September 25, 2015.
32. U.S. Food and Drug Administration. Metal-on-metal hip implants: FDA safety communication, 2013. Available at: www.fda.gov/MedicalDevices/Safety/AlertsandNotices/ ucm335775.htm Accessed October 14, 2015.

33. Branham WS, Fishman R, Streck RD, Medlock KL, De George JJ, Sheehan DM. ICI 182,780 inhibits endogenous estrogen-dependent rat uterine growth and tamoxifeninduced developmental toxicity. Biol Reprod 1996;54: 160-167.

34. Marques MM, Beland FA. Identification of tamoxifenDNA adducts formed by 4-hydroxytamoxifen quinone methide. Carcinogenesis 1997;18:1949-1954.

35. Kedar RP, Bourne TH, Powles TJ, et al. Effects of tamoxifen on uterus and ovaries of postmenopausal women in a randomised breast cancer prevention trial. Lancet 1994; 343:1318-1321.

36. Deligdisch L. Hormonal pathology of the endometrium. Mod Pathol 2000;13:285-294.

37. U.S. Food and Drug Administration. Drug labeling: Nolvadex. Available at: www.accessdata.fda.gov/drugsatfda docs/label/2006/017970s054lbl.pdf Accessed September 25, 2015.

38. U.S. Food and Drug Administration. Drug Labeling for Fareston $^{\circledR}$. Available at: www.accessdata.fda.gov/drug satfda_docs/label/2011/020497s006lbl.pdf Accessed September 25, 2015.

39. Hay M, Thomas DW, Craighead JL, Economides C, Rosenthal J. Clinical development success rates for investigational drugs. Nat Biotechnol 2014;32:40-51.

40. American Cancer Society. Cancer Facts \& Figures 2015. Available at: www.cancer.org/acs/groups/content/@editorial/ documents/document/acspc-044552.pdf Accessed September 25, 2015.

41. Bruno R, Claret L. On the use of change in tumor size to predict survival in clinical oncology studies: Toward a new paradigm to design and evaluate phase II studies. Clin Pharmacol Ther 2009;86:136-138.

42. Claret L, Lu J, Bruno R, Sikorski S, Hei Y, Sun Y. Simulation of phase III studies of motesanib $125 \mathrm{mg}$ once daily (QD) plus carboplatin/paclitaxel (CPM) or bevacizumab plus carboplatin/paclitaxel (CPB) versus carboplatin/paclitaxel (CP) in first-line non-small cell lung cancer (NSCLC) using a public domain drug-disease modeling framework and phase II data. 2010 ASCO Annual Meeting. Available at: http://meetinglibrary.asco.org/ content/47606-74 Accessed October 14, 2015.

43. Khurana S, Needham J, Park S, et al. Novel approach for differential diagnosis of HIV infections in the face of vaccine-generated antibodies: Utility for detection of diverse HIV-1 subtypes. J Acquir Immune Defic Syndr 2006; 43:304-312.

44. Penezina O, Krueger NX, Rodriguez-Chavez IR, et al. Performance of a redesigned HIV Selectest enzyme-linked immunosorbent assay optimized to minimize vaccineinduced seropositivity in HIV vaccine trial participants. Clin Vaccine Immunol 2014;21:391-398.

45. Einstein AJ, Henzlova MJ, Rajagopalan S. Estimating risk of cancer associated with radiation exposure from 64-slice computed tomography coronary angiography. JAMA 2007; 298:317-323.

46. U.S. Preventive Services Task Force. Breast cancer screening draft recommendations. Available at: http:// screeningforbreastcancer.org/ Accessed September 17, 2015. 
47. U.S. Food and Drug Administration. Mammography Quality Standards Act and Program. Available at: www .fda.gov/Radiation-EmittingProducts/MammographyQuality StandardsActandProgram/ Accessed September 25, 2015.

48. Park S, Jennings R, Liu H, Badano A, Myers K. A statistical, task-based evaluation method for three-dimensional $\mathrm{x}$ ray breast imaging systems using variable-background phantoms. Med Phys 2010;37:6253-6270.

49. Young S, Bakic PR, Myers KJ, Jennings RJ, Park S. A virtual trial framework for quantifying the detectability of masses in breast tomosynthesis projection data. Med Phys 2013;40:051914.

50. Drukteinis JS, Mooney BP, Flowers CI, Gatenby RA. Beyond mammography: New frontiers in breast cancer screening. Am J Med 2013;126:472-479.

51. Rupcich F, Badal A, Kyprianou I, Schmidt TG. A database for estimating organ dose for coronary angiography and brain perfusion CT scans for arbitrary spectra and angular tube current modulation. Med Phys 2012;39: 5336-5346.

52. Gee RE, Wood SF, Schubert KG. Women's health, pregnancy, and the U.S. Food and Drug Administration. Obstet Gynecol 2014;123:161-165.

53. Andrade SE, Gurwitz JH, Davis RL, et al. Prescription drug use in pregnancy. Am J Obstet Gynecol 2004;191: 398-407.

54. Centers for Disease Control and Prevention. Unintended pregnancy prevention. Available at: www.cdc.gov/repro ductivehealth/unintendedpregnancy/ Accessed September $17,2015$.

55. Sinha V, Zhao P, Huang SM, Zineh I. Physiologically based pharmacokinetic modeling: From regulatory science to regulatory policy. Clin Pharmacol Ther 2014;95:478480.

56. Clewell HJ, Gentry PR, Covington TR, Sarangapani R, Teeguarden JG. Evaluation of the potential impact of ageand gender-specific pharmacokinetic differences on tissue dosimetry. Toxicol Sci 2004;79:381-393.

57. Andrade SE, Raebel MA, Brown J, et al. Outpatient use of cardiovascular drugs during pregnancy. Pharmacoepidemiol Drug Saf 2008;17:240-247.

58. Cooper WO, Willy WE, Pont SJ, Ray WA. Increasing use of antidepressants in pregnancy. Am J Obstet Gynecol 2007; 196:544.e1-544.e5.

59. Cooper WO, Hickson GB, Ray WA. Prescriptions for contraindicated category $\mathrm{X}$ drugs in pregnancy among women enrolled in TennCare. Pediatr Perinat Epidemiol 2004;18:106-111.

60. Eguale T, Buckeridge DL, Winslade NE, Benedetti A, Hanley JA, Tamblyn R. Drug, patient, and physician characteristics associated with off-label prescribing in primary care. Arch Intern Med 2012;172:781-788.

61. Staffa JA, Dal Pan GJ. Regulatory innovation in postmarketing risk assessment and management. Clin Pharmacol Ther 2012;91:555-557.

62. Federal Register. Food and Drug Administration. Study approaches and methods to evaluate the safety of drugs and biological products during pregnancy in the post-approval setting; Notice, 79 FR 9469. February 19, 2014. Available at: https://federalregister.gov/a/2014-03589 Accessed September 25, 2015.

63. Agency for Healthcare Research \& Quality. Birth defects may be linked to high blood pressure, not use of ACE inhibitors in early pregnancy. Available at: http:// archive.ahrq.gov/news/newsroom/press-releases/2011/ ehcdefects.html Accessed September 25, 2015.

64. Cooper WO, Hernandez-Diaz S, Arbogast PG, et al. Major congenital malformations after first-trimester exposure to ACE inhibitors. N Engl J Med 2006;354:2443-2451.

65. Mitchell AA. Fetal risk from ACE inhibitors in the first trimester. BMJ 2011;343:d6667.

66. US Food and Drug Administration. Approved Labeling for Zestril. Available at: www.accessdata.fda.gov/drug satfda_docs/label/2012/019777s062lbl.pdf Accessed September 24, 2015.

67. Podymow T, August P. Update on the use of antihypertensive drugs in pregnancy. Hypertension 2008;51:960-969.

68. Tavris DR, Jacobs S. Postmarket surveillance of vascular closure devices: The FDA perspective on VCDs and the importance of continued surveillance. Cardiac Interventions Today, March/April 2013. Available at: http://citoday.com/ pdfs/cit0313_F6_Tavris.pdf Accessed October 19, 2015.

69. Linville D. Osteoporotic fractures. South Med J 2002; 95:588-592.

70. Dec WG. Leaning toward a better understanding of CRT in women. J Am Coll Cardiol 2014;64:895-897.

71. Strauss, DG. Filling information gaps for women in medical device clinical trials. Available at: http://blogs .fda.gov/fdavoice/index.php/2014/06/filling-informationgaps-for-women-in-medical-device-clinical-trials/ Accessed September 25, 2015.

72. Tracy CM, Epstein AE, Darbar D, et al. 2012 ACCF/ AHA/HRS Focused update of the 2008 guidelines for device-based therapy of cardiac rhythm abnormalities: A report of the American College of Cardiology Foundation/ American Heart Association Task Force on Practice Guidelines. Heart Rhythm 2012;9:1737-1753.

73. U.S.Congress. Dietary Supplement Health and Education Act of 1994. Available at: www.fda.gov/regulatoryinfor mation/legislation/federalfooddrugandcosmeticactfdcact/ significantamendmentstothefdcact/ucm148003.htm Accessed September 25, 2015.

74. Food and Drug Administration. FDA announces rule prohibiting sale of dietary supplements containing ephedrine alkaloids effective. April 12. Available at: www.fda.gov/ NewsEvents/Newsroom/PressAnnouncements/2004/ucm10 8281.htm Accessed September 25, 2015.

75. Food and Drug Administration. FDA challenges marketing of DMAA products for lack of safety evidence. Available at: www.fda.gov/NewsEvents/Newsroom/Press Announcements/ucm302133.htm Accessed September 25, 2015.

76. Warber SL, Wunder J, Schiller A, Sandretto A, Uhley V, Bolling S. Use and effect of Ephedra weight loss products-A pilot cohort study. Focus Altern Complement Ther 2003;8:550-551.

77. Mahady G, Parrot J, Lee C, Yun GS, Dan A. Botanical dietary supplement use in peri- and postmenopausal women. Menopause 2003;10:65-72.

78. Mahady GB, Low DT, Barrett ML, et al. United States Pharmacopeia review of the black cohosh case reports of hepatotoxicity. Menopause 2008;15:628-638.

79. Betz J, Anderson L, Avigan M, et al. Black cohosh: Considerations of safety and benefit. Available at: https:// ods.od.nih.gov/attachments/nt2000027_betz.pdf Accessed October 14, 2015.

80. Federal Register. Food and Drug Administration. Food labeling; Gluten-free labeling of foods; Final rule. August 5, 
2013; 21 CFR 10. Available at: https://federalregister.gov/a/ 2013-18813 Accessed September 8, 2014.

81. Rallabhandi P. Gluten and celiac disease-An immunological perspective. J AOAC Int 2012;95:349-355.

82. McGrath SC, Sharma GM, Rallabhandi PV, Callahan JH, Williams KM, Ross MM. Evaluation of digested wheat gluten as a proposed reference material for ELISA analysis. J Biomol Tech 2013;24(Suppl): S54.

83. Sharma GM, Rallabhandi P. The effects of processing on gluten from wheat, rye and barley and its detection in foods. Chapter 36. In: Preedy V, ed. Processing and Impact on Active Components in Food. San Diego, CA: Academic Press, 2015:303-308.

84. Rallabhandi P, Sharma G, Pereira M, Williams KM. Immunological characterization of the gluten fractions and their hydrolysates from wheat, rye and barley. J Agric Food Chem 2015;63:1825-1832.

85. Reilly NR, Green PH. Epidemiology and clinical presentations of celiac disease. Semin Immunopathol 2012;34: 473-478.

86. Benton RE, Sale M, Flockhart DA, Woosley RL. Greater quinidine-induced QTc interval prolongation in women. Clin Pharmacol Ther 2000;67:413-418.

87. Rodriguez I, Kilborn MJ, Liu XK, Pezzullo JC, Woosley RL. Drug-induced QT prolongation in women during the menstrual cycle. JAMA 2001;285:1322-1326.

88. Katchman AN, Koerner J, Tosaka T, Woosley RL, Ebert SN. Comparative evaluation of HERG currents and QT intervals following challenge with suspected torsadogenic and nontorsadogenic drugs. J Pharmacol Exp Ther 2006; 316:1098-1106.

89. Dinh P, Sun J, Bai S, Kordzakhia G. Sex-related differences in QTc effects potential of drugs. Rev Recent Clin Trials 2011;6:220-227.

90. United States General Accounting Office. Drug safety: Most drugs withdrawn in recent years had greater health risks for women, 2001. Available at: www.gao.gov/ products/GAO-01-286R Accessed November 6, 2014.

91. Johannesen L, Vicente J, Mason JW, et al. Differentiating drug-induced multichannel block on the electrocardiogram: Randomized study of dofetilide, quinidine, ranolazine, and verapamil. Clin Pharmacol Ther 2014;96:549-558.

92. Johannesen L, Vicente J, Gray RA, et al. Improving the assessment of heart toxicity for all new drugs through translational regulatory science. Clin Pharmacol Ther 2014; 95:501-508.

93. Vicente J, Johannesen L, Mason JW, et al. Comprehensive $\mathrm{T}$ wave morphology assessment in a randomized clinical study of dofetilide, quinidine, ranolazine, and verapamil. J Am Heart Assoc 2015;4:pii:e001615.

94. Vicente J, Simlund J, Johannesen L, et al. Investigation of potential mechanisms of sex differences in quinidineinduced torsade de pointes risk. J Electrocardiol 2015;48: 533-538.

95. Slamon DJ, Leyland-Jones B, Shak S, et al. Use of chemotherapy plus a monoclonal antibody against HER2 for metastatic breast cancer that overexpresses HER2. N Engl J Med 2001;344:783-792.

96. ElZarrad MK, Mukhopadhyay P, Mohan N, et al. Trastuzumab alters the expression of genes essential for cardiac function and induces ultrastructural changes of cardiomyocytes in mice. PLoS One 2013;8:e79543.

97. U.S. Government Accountability Office. Women sufficiently represented in new drug testing, but FDA oversight needs improvement, 2001. Available at: www.gao.gov/ products/GAO-01-754 Accessed September 25, 2015.

98. Yang Y, Carlin AS, Faustino PJ, et al. Participation of women in clinical trials for new drugs approved by the food and drug administration in 2000-2002. J Womens Health (Larchmt) 2009;18:303-310.

99. Pinnow E, Sharma P, Parekh A, Gevorkian N, Uhl K. Increasing participation of women in early phase clinical trials approved by the FDA. Womens Health Issues 2009; 19:89-93.

100. Poon R, Khanijow K, Umarjee S, et al. Participation of women and sex analyses in late-phase clinical trials of new molecular entity drugs and biologics approved by the FDA in 2007-2009. J Womens Health (Larchmt) 2013; 22:604-616.

101. Eshera N, Itana H, Zhang L, Soon G. Demographics of clinical trials participants in pivotal clinical trials for new molecular entity drugs and biologics approved by FDA from 2010 to 2012. Am J Ther 2015;22:435-455.

102. Gallauresi B, Khanijow K, Umarjee S, Parekh A. A 5-year review of approved cardiovascular medical devices: Are women and ethnic minorities adequately represented? Cardiovasc Revasc Med 2011;12:e36.

103. Gallauresi B, Dave D. TCT-358 Food and Drug Administration approved cardiovascular medical devices: A ten year review of the participation of women and ethnic subgroups. J Am Coll Cardiol 2012;60(17_S)B102.

104. U.S. Food and Drug Administration. FDA Report: Collection, analysis, and availability of demographic subgroup data for FDA-approved medical products, 2013. Available at: www.fda.gov/downloads/RegulatoryInformation/Legis lation/FederalFoodDrugandCosmeticActFDCAct/Significant AmendmentstotheFDCAct/FDASIA/UCM365544.pdf Accessed September 25, 2015.

105. Food and Drug Administration. Drug trials snapshot, 2014. Available at: www.fda.gov/Drugs/Information OnDrugs/ucm412998.htm Accessed December 5, 2014.

106. Bylander J. CDRH explores recommendations for genderspecific cardiovascular studies. The Gray Sheet: Medical devices, diagnostics \& instrumentation 2008:16.

107. Federal Register. U.S. Food and Drug Administration. Sex differences in the cardiovascular device trials; Public Workshop. November 26, 2008, E8-28169. Available at: www.regulations.gov/\#!documentDetail;D=FDA-2008-N0038-0089 Accessed September 25, 2015.

108. Coakley M, Fadiran EO, Parrish LJ, Griffith RA, Weiss E, Carter C. Dialogues on diversifying clinical trials: Successful strategies for engaging women and minorities in clinical trials. J Womens Health (Larchmt) 2012;21:713-716.

109. Society for Women's Health and FDA Office of Women's Health. Dialogues on diversifying clinical trials: Successful strategies for engaging women and minorities in clinical trials. Available at: www.fda.gov/downloads/ ScienceResearch/SpecialTopics/WomensHealthResearch/ UCM334959.pdf Accessed September 25, 2015.

110. Yang L, Li Y, Hong H, et al. Sex differences in the expression of drug metabolizing and transporter genes in human liver. Drug Metab Toxicol 2012;3:1-9.

111. Kwekel JC, Desai VG, Moland CL, Vijay V, Fuscoe JC. Sex differences in kidney gene expression during the life cycle of F344 rats. Biol Sex Differ 2013;4:14.

112. Yu Y, Fuscoe JC, Zhao C, et al. A rat RNA-Seq transcriptomic BodyMap across 11 organs and 4 developmental stages. Nat Commun 2014;5:3230. 
113. Marti HP, Fuscoe JC, Kwekel JC, Anagnostopoulu A, Scherer A. Metzincins and related genes in experimental renal ageing: Towards a unifying fibrosis classifier across species. Nephrol Dial Transplant 2014;29:1177-1185.

114. Kwekel JC, Desai VG, Moland CL, Vijay V, Fuscoe JC. Life cycle analysis of kidney gene expression in male F344 rats. PLoS One 2013;6:e75305.

115. Kwekel JC, Vijay V, Desai VG, Moland CL, Fuscoe JC. Age and sex differences in kidney microRNA expression during the life span of F344 rats. Biol Sex Differ 2015;6:1.

116. Arasappan D, Tong W, Mummaneni P, Fang H, Amur S. Meta-analysis of microarray data using a pathway-based approach identifies a 37-gene expression signature for systemic lupus erythematosus in human peripheral blood mononuclear cells. BMC Med 2011;9:65.

117. Gavrielides MA, Gallas BD, Lenz P, Badano A, Hewitt SM. Observer variability in the interpretation of HER2/ neu immunohistochemical expression with unaided and computer-aided digital microscopy. Arch Pathol Lab Med 2011;135:233-242.

118. Wilson P. Development and validation of a liquid chromatographic method for the simultaneous determination of estradiol, estriol, estrone, and progesterone in pharmaceutical preparations. J AOAC Int 2009;92:846-854.

119. FDA Office of Women's Health. List of Research Science Program Awards. Available at: www.fda.gov/Science Research/SpecialTopics/WomensHealthResearch/ucm246 235.htm Accessed September 25, 2015.

120. Guo J, Saylor DM, Glaser EP, Patwardhan DV. Impact of artificial plaque composition on drug transport. J Pharm Sci 2013;102:1905-1914.

121. Zhang Q, Rajan SS, Tyner KM, et al. Effects of iron oxide nanoparticles on biological responses and MR imaging properties in human mammary healthy and breast cancer epithelial cells. J Biomed Mater Res B Appl Biomater 2015 [Epub ahead of print]; DOI: 10.1002/jbm.b.33450

122. Szarfman A, Machado SG, O'Neill RT. Use of screening algorithms and computer systems to efficiently signal higher-than-expected combinations of drugs and events in the US FDA's spontaneous reports database. Drug Saf 2002;25:381-392.

123. Saperstein S. Factors related to listeriosis prevention in pregnant women: A mixed methods exploratory study, 2010. Dissertation at the University of Maryland. Available at: http://drum.lib.umd.edu/handle/1903/10348. Accessed September 25, 2015.

124. Ma L, Norton MG, Mahmood I, et al. Transplacental transfer of hepatitis B neutralizing antibody during preg- nancy in an animal model: Implications for newborn and maternal health. Hepat Res Treat 2014;2014:159206.

125. FDA Office of Women’s Health. ¡Nunca Más! Novelas. Available at: www.fda.gov/ForConsumers/ByAudience/ ForWomen/ucm269846.htm Accessed September 25, 2015.

126. FDA Office of Women's Health. College Women's Health. Available at: www.fda.gov/ForConsumers/ByAudience/For Women/TakeTimetoCareProgram/ucm387961.htm Accessed September 25, 2015.

127. FDA Office of Women's Health. Free publications for women. Available at: www.fda.gov/ForConsumers/By Audience/ForWomen/FreePublications/default.htm Accessed December 5, 2014.

128. Food and Drug Administration Office of Women's Health. Women's Health Research Roadmap. Available at: http:// www.fda.gov/ScienceResearch/SpecialTopics/Womens HealthResearch/ucm478266.htm Accessed February 8, 2016.

129. U.S. Food and Drug Administration and National Institutes of Health. Memorandum of understanding between the U.S. Department of Health and Human Services Food and Drug Administration Office of Women's Health and the National Institutes of Health Office of Research on Women's Health. Available at: www.fda.gov/AboutFDA/ PartnershipsCollaborations/MemorandaofUnderstanding MOUs/DomesticMOUs/ucm430722.htm Accessed September 25, 2015.

130. U.S. Food and Drug Administration and Karolinksa Institutet. Memorandum of understanding between U.S. Department of Health and Human Services Food and Drug Administration Office of Women's Health and Karolinksa Institutet and Stockholms Lans Lans Landsting/Halso-ocj Sjukvardsforvaltningen (Stockholm County Council/Health care Administration). Available at: www.fda.gov/AboutFDA/ PartnershipsCollaborations/MemorandaofUnderstanding MOUs/OtherMOUs/ucm396397.htm Accessed September 25, 2015.
Address correspondence to: Emmanuel O. Fadiran, PhD Office of Women's Health Food and Drug Administration (FDA) WO Building 32, Room 2312 10903 New Hampshire Avenue Silver Spring, MD 20993-0002

E-mail: emmanuel.fadiran@fda.hhs.gov 